\title{
Hydrogeophysics and remote sensing for the design of hydrogeological conceptual models in hard rocks - Sardón catchment (Spain)
}

\author{
Alain P. Francés a,*, Maciek W. Lubczynski ${ }^{\text {a }}$, Jean Roy ${ }^{\text {b }}$, \\ Fernando A.M. Santos ${ }^{c}$, Mohammad R. Mahmoudzadeh Ardekani ${ }^{\mathrm{d}}$ \\ a Faculty of Geo-Information Science and Earth Observation (ITC), University of Twente, P.O. Box 217, 7500 AE Enschede, The Netherlands \\ b IGP, cp 48671, csp van Horne, Outremont QC, Canada H2V $4 T 9$ \\ ' IDL-Universidade de Lisboa, Fac. Ciências, Edifício C8, CampoGrande, 1749-016 Lisboa, Portugal \\ d Signal and Image Centre, Royal Military Academy, 30 Avenue de la Renaissance, 1000 Brussels, Belgium
}

\section{A R T I C L E I N F O}

\section{Article history:}

Received 20 November 2013

Accepted 25 August 2014

Available online 6 September 2014

\section{Keywords:}

Hard rocks

Remote sensing

Hydrogeophysics

Aquifer geometry and parameters

Hydrogeological conceptual model

\begin{abstract}
A B S T R A C T
Hard rock aquifers are highly heterogeneous and hydrogeologically complex. To contribute to the design of hydrogeological conceptual models of hard rock aquifers, we propose a multi-techniques methodology based on a downward approach that combines remote sensing (RS), non-invasive hydrogeophysics and hydrogeological field data acquisition. The proposed methodology is particularly suitable for data scarce areas. It was applied in the pilot research area of Sardón catchment $\left(80 \mathrm{~km}^{2}\right)$ located west of Salamanca (Spain). The area was selected because of hard-rock hydrogeology, semi-arid climate and scarcity of groundwater resources. The proposed methodology consisted of three main steps. First, we detected the main hydrogeological features at the catchment scale by processing: (i) a high resolution digital terrain model to map lineaments and to outline fault zones; and (ii) high-resolution, multispectral satellite QuickBird and WorldView-2 images to map the outcropping granite. Second, we characterized at the local scale the hydrogeological features identified at step one with: i) ground penetrating radar (GPR) to assess groundwater table depth complementing the available monitoring network data; ii) 2D electric resistivity tomography (ERT) and frequency domain electromagnetic (FDEM) to retrieve the hydrostratigraphy along selected survey transects; iii) magnetic resonance soundings (MRS) to retrieve the hydrostratigraphy and aquifer parameters at the selected survey sites. In the third step, we drilled 5 boreholes ( 25 to $48 \mathrm{~m}$ deep) and performed slug tests to verify the hydrogeophysical interpretation and to calibrate the MRS parameters. Finally, we compiled and integrated all acquired data to define the geometry and parameters of the Sardón aquifer at the catchment scale.

In line with a general conceptual model of hard rock aquifers, we identified two main hydrostratigraphic layers: a saprolite layer and a fissured layer. Both layers were intersected and drained by fault zones that control the hydrogeology of the catchment. The spatial discontinuities of the saprolite layer were well defined by RS techniques while subsurface geometry and aquifer parameters by hydrogeophysics. The GPR method was able to detect shallow water table at depth between 1 and $3 \mathrm{~m}$ b.g.s. The hydrostratigraphy and parameterization of the fissured layer remained uncertain because ERT and FDEM geophysical methods were quantitatively not conclusive while MRS detectability was restricted by low volumetric water content. The proposed multi-technique methodology integrating cost efficient RS, hydrogeophysics and hydrogeological field investigations allowed us to characterize geometrically and parametrically the Sardón hard rock aquifer system, facilitating the design of hydrogeological conceptual model of the area.
\end{abstract}

C 2014 Elsevier B.V. All rights reserved.

\section{Introduction}

Although groundwater resources in hard rock aquifers are generally limited in term of productivity, they are strategically important in many regions of the world because they constitute a unique source of water

\footnotetext{
* Corresponding author. Tel.: + 31534874277.

E-mail address: a.p.frances@utwente.nl (A.P. Francés).
}

supply for population and agriculture (Cook, 2003; Singhal and Gupta, 2010). Hard rock aquifers are characterized by high heterogeneity, which leads to difficulties in groundwater prospecting, boreholes implementation and water resources management. This heterogeneity exhibit a complex pattern that results from the interaction of factors such as mineralogy and texture of lithologies, regional and local tectonics, and paleoclimate. An overall layout of the general conceptual model of hard rock aquifers, both from horizontal extent and depth-wise structure, was described by e.g. Lloyd (1999), Dewandel et al. (2006) and 